\title{
Artificial intelligence to codify lung CT in Covid-19 patients
}

\author{
Maria Paola Belfiore ${ }^{1}$. Fabrizio Urraro ${ }^{1} \cdot$ Roberta Grassi $^{1}$. Giuliana Giacobbe ${ }^{1} \cdot$ Gianluigi Patelli $^{2}$. \\ Salvatore Cappabianca ${ }^{1} \cdot$ Alfonso Reginelli $^{1}$
}

Received: 27 March 2020 / Accepted: 2 April 2020 / Published online: 4 May 2020

C) Italian Society of Medical Radiology 2020

\begin{abstract}
The spread of severe acute respiratory syndrome coronavirus 2 (SARS-CoV-2) has already assumed pandemic proportions, affecting over 100 countries in few weeks. A global response is needed to prepare health systems worldwide. Covid-19 can be diagnosed both on chest X-ray and on computed tomography (CT). Asymptomatic patients may also have lung lesions on imaging. CT investigation in patients with suspicion Covid-19 pneumonia involves the use of the high-resolution technique (HRCT). Artificial intelligence (AI) software has been employed to facilitate CT diagnosis. AI software must be useful categorizing the disease into different severities, integrating the structured report, prepared according to subjective considerations, with quantitative, objective assessments of the extent of the lesions. In this communication, we present an example of a good tool for the radiologist (Thoracic VCAR software, GE Healthcare, Italy) in Covid-19 diagnosis (Pan et al. in Radiology, 2020. https://doi.org/10.1148/radiol.2020200370). Thoracic VCAR offers quantitative measurements of the lung involvement. Thoracic VCAR can generate a clear, fast and concise report that communicates vital medical information to referring physicians. In the post-processing phase, software, thanks to the help of a colorimetric map, recognizes the ground glass and differentiates it from consolidation and quantifies them as a percentage with respect to the healthy parenchyma. AI software therefore allows to accurately calculate the volume of each of these areas. Therefore, keeping in mind that CT has high diagnostic sensitivity in identifying lesions, but not specific for Covid-19 and similar to other infectious viral diseases, it is mandatory to have an AI software that expresses objective evaluations of the percentage of ventilated lung parenchyma compared to the affected one.
\end{abstract}

Keywords Sars-Cov-2 Artificial intelligence $\cdot$ Structured report

\section{Introduction}

The World Health Organization (WHO) on March 11, 2020, has communicated the novel coronavirus (Covid-19) outbreak a global pandemic. WHO Director-General, Tedros Adhanom Ghebreyesus, observed that over the past 2 weeks, the number of cases increased 13-fold [2]. The spread of severe acute respiratory syndrome coronavirus 2 (SARSCoV-2) has already assumed pandemic proportions, affecting over 100 countries in few weeks. A global response is needed to prepare health systems worldwide. Although

Alfonso Reginelli

alfonso.reginelli@hotmail.com

1 Department of Precision Medicine, University of Campania Luigi Vanvitelli, 80138 Naples, Italy

2 Radiology Department, ASST Bolognini Hospital, Bergamo Est, Italy containment measures in China have reduced all new cases, this reduction has not occurred elsewhere and Italy has been particularly hard hit. There is now serious concern regarding the ability of the Italian national health system to respond effectively to the needs of infected patients requiring intensive care for Covid-19 pneumonia. The percentage of intensive care unit (ICU) patients reported daily in Italy between March 1 and March 11, 2020, was constantly between 9 and $11 \%$ of the patients infected. Since February 21 , in Italy the number of patients infected closely follows an exponential trend [3,4] and Covid-19 diagnosis is performed by detecting pathogenic samples and traces of the specific immune response by means of a saliva sample in symptomatic patients. Usually it takes 2 days to get the result of the swab which is why you are not timely in response. Currently, the screening work is passive and is mainly based on symptoms, but unfortunately as the number of asymptomatic patients increases, prevention and control of the epidemic become 
even more difficult. Overcrowded medical establishments are further difficulties in preventing the epidemic and seriously exposed. Therefore, there is a very high risk of crossinfection between medical staff and patients [5, 6]. Covid19 can be diagnosed both on chest X-ray and on computed tomography (CT) [7]. Asymptomatic patients may also have lung lesions on imaging. CT investigation in patients with suspicion Covid-19 pneumonia involves the use of the highresolution technique (HRCT). HRCT is the most accurate technique in identifying pathognomic findings of interstitial pneumonia as ground glass areas, crazy paving, nodules and consolidations, mono- or bilateral, patchy or multifocal, central and/or peripheral distribution, declivous or nondeclivous [7-11]. Other findings, such as pleural effusion, pericardial effusion and mediastinal lymphadenopathy, are also possible. Often Covid-19 patients already suffer from other lung diseases $[12,13]$. CT is widely used, has rapid acquisition speed and high sensitivity, which has led to a large number of patients referred to imaging and the number of confirmed patients whose evolution must be followed. However, after examination, disinfection of CT room is mandatory and wait on average $20 \mathrm{~min}$, time necessary for the exchange of air to secure the equipment and the environments. Therefore, CT use should be limited to the resolution of complex clinical problems or to patients with first negative swab, whose symptoms need urgent therapy. Artificial intelligence (AI) software has been employed to facilitate CT diagnosis. Unfortunately, Covid-19 patients have similar imaging characteristics as interstitial pneumonia caused by other viruses and AI software programs are not able to differentiate Covid-19 from other viral pneumonias. Furthermore, common to all big data-based applications, all deep learning methods have lack of transparency and interpretability and it is impossible to determine what imaging features are being used to determine the output.

However, advantages of software are automated measurements of wall thickness for intuitive airway analysis, lobe segmentation and visualization. Beside clinical procedures and treatments, AI promises a new paradigm for health care, with different tools that are built upon machine learning (ML) algorithms and support the decision-making processes. AI software must be useful categorizing the disease into different severities, integrating the structured report [14], prepared according to subjective considerations, with quantitative, objective assessments of the extent of the lesions.

In this communication, we present an example of a good tool for the radiologist (Thoracic VCAR software, GE Healthcare, Italy) in Covid-19 diagnosis [1]. Thoracic VCAR offers quantitative measurements of the lung involvement. Thoracic VCAR can generate a clear, fast and concise report that communicates vital medical information to referring physicians. In the post-processing phase, software, thanks to the help of a colorimetric map, recognizes the ground glass and differentiates it from consolidation and quantifies them as a percentage with respect to the healthy parenchyma. AI software therefore allows to accurately calculate the volume of each of these areas [1, 14]. This "objective" information is useful for evaluating regression or progression disease in response to drug therapy as well as evaluating the effectiveness of pronation maneuvers for alveolar recruitment in ICU patients. It is therefore desirable to have an automatic system to perform and accurate detection of the Covid-19 using chest-CT. Moreover, during the follow-up HRCT examination could precisely quantify the course of the disease and evaluates the effectiveness of the experimental trial and the patient's prognosis (Figs. 1, 2). On the basis of the scientific evidence acquired so far, it is also intended to underline that, considering the nonspecificity of HRCT patterns of Covid-19 pneumonia that do not allow to express a diagnostic judgment of certainty, the chest HRCT examination cannot be considered a substitute for the RTPCR test in the diagnosis of Covid-19 nor used as a means of clinical screening, but it represents a good support [15].

\section{Conclusion}

Therefore, keeping in mind that CT has high diagnostic sensitivity in identifying lesions, but not specific for Covid-19 and similar to other infectious viral diseases, it is mandatory to have an AI software that expresses objective evaluations of the percentage of ventilated lung parenchyma compared to the affected one. 

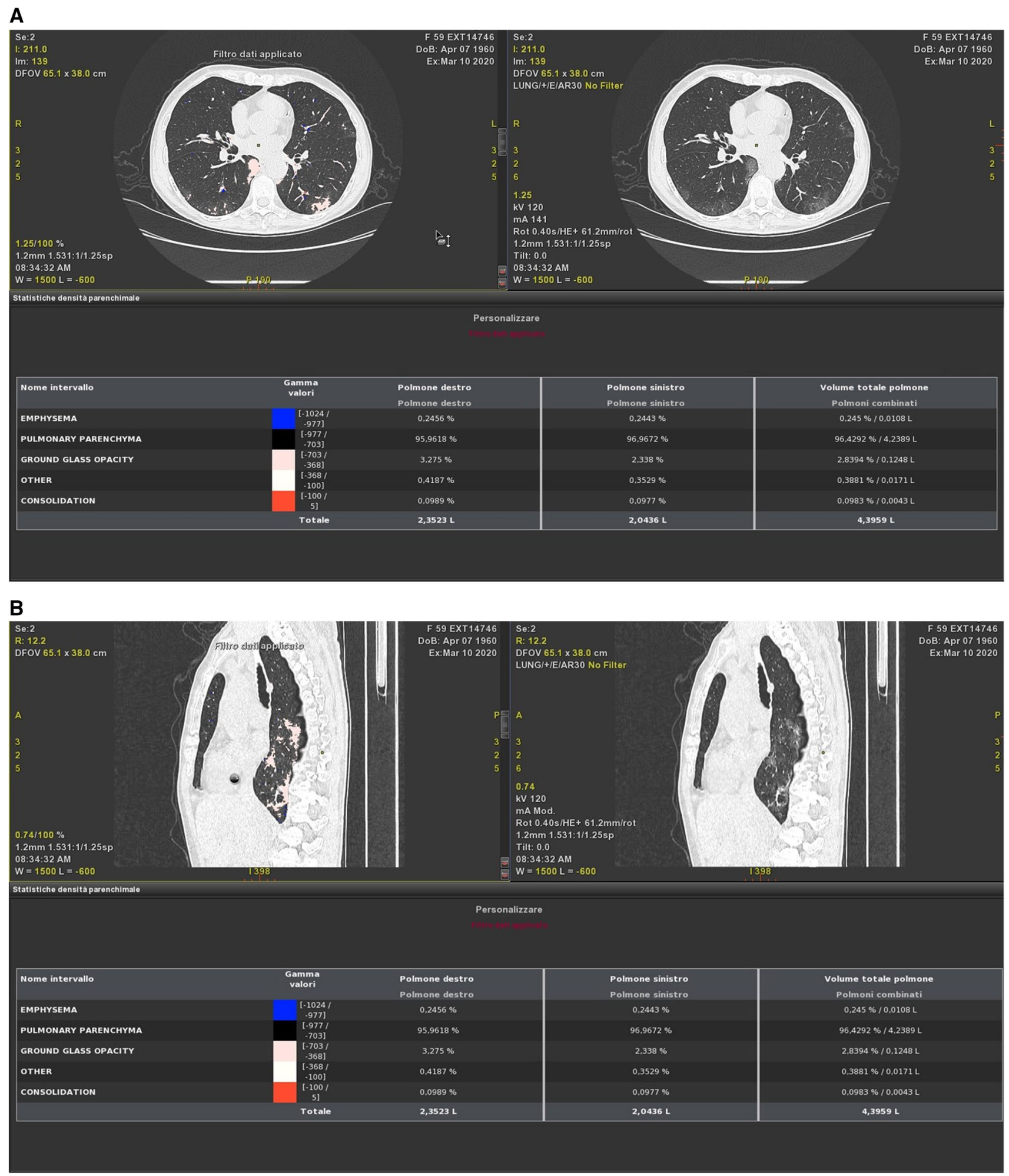

Fig. 1 Example of lung analysis in a patient COVID-19 with the Thoracic VCAR software in axial (a) and sagittal (b) planes 


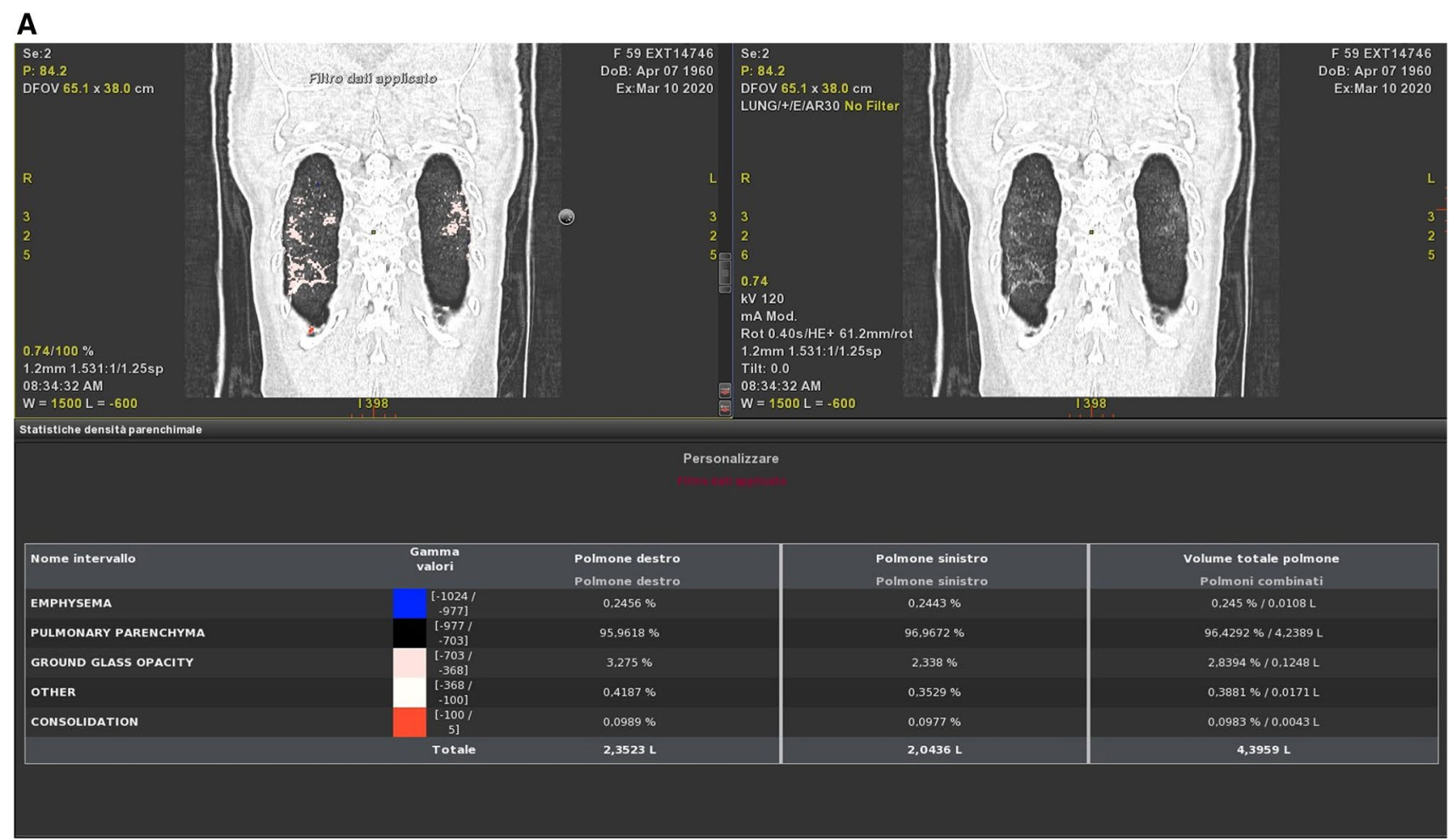

\section{B}

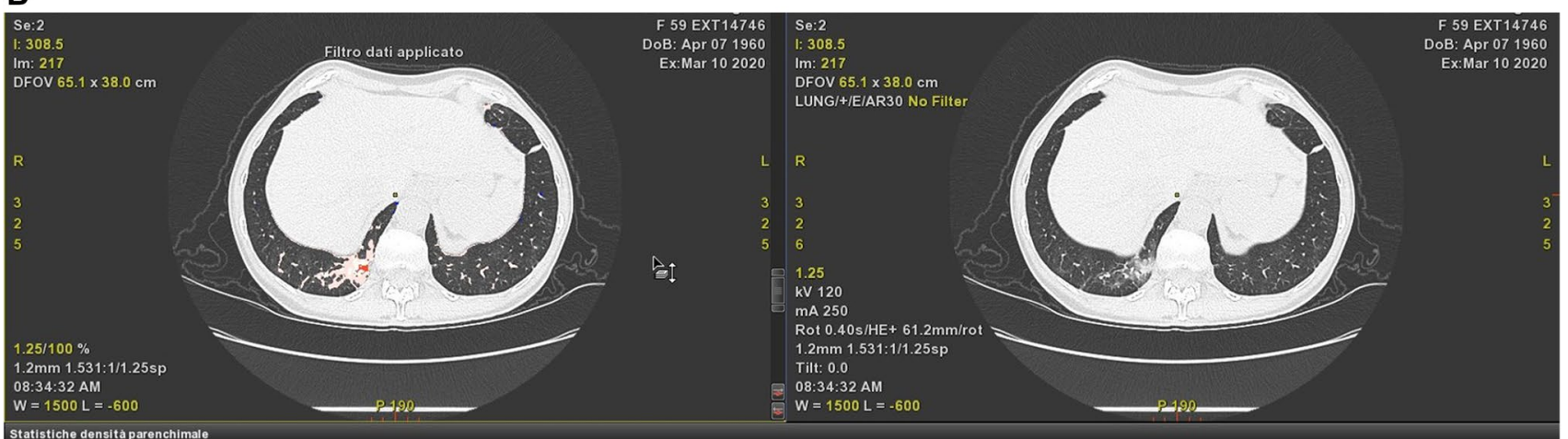

Statistiche densita parenchimal

Personalizzare

\begin{tabular}{|c|c|c|c|c|}
\hline Nome intervallo & $\begin{array}{c}\text { Gamma } \\
\text { valori }\end{array}$ & $\begin{array}{l}\text { Polmone destro } \\
\text { Polmone destro }\end{array}$ & $\begin{array}{l}\text { Polmone sinistro } \\
\text { Polmone sinistro }\end{array}$ & $\begin{array}{l}\text { Volume totale polmone } \\
\text { Polmoni combinati }\end{array}$ \\
\hline EMPHYSEMA & $\begin{array}{c}{[-1024]} \\
.977]\end{array}$ & $0,2456 \%$ & $0,2443 \%$ & $0.245 \% / 0.0108 \mathrm{~L}$ \\
\hline PULMONARY PARENCHYMA & $\begin{array}{l}{[-977\}} \\
-703]\end{array}$ & $95.9618 \%$ & $96,9672 \%$ & $96.4292 \% / 4.2389 \mathrm{~L}$ \\
\hline GROUND GLASS OPACITY & $\begin{array}{l}{[-703\}} \\
-368]\end{array}$ & $3.275 \%$ & $2,338 \%$ & $2,8394 \% / 0.1248 \mathrm{~L}$ \\
\hline OTHER & $\begin{array}{l}{[-368\}} \\
-100]\end{array}$ & $0.4187 \%$ & $0,3529 \%$ & $0,3881 \% / 0,0171 L$ \\
\hline \multirow[t]{2}{*}{ CONSOLIDATION } & $\begin{array}{l}{[-100 /} \\
5]\end{array}$ & $0,0989 \%$ & $0.0977 \%$ & $0.0983 \% / 0,0043 L$ \\
\hline & Totale & $2,3523 \mathrm{~L}$ & $2,0436 \mathrm{~L}$ & 4,3959 L \\
\hline
\end{tabular}

Fig. 2 Image shows an example of the automatic analysis of pathological areas with highlighted of the ground glass (pink) (a) from the parenchymal consolidation area (red) (b) using a colorimetric map 
Acknowledgements Thanks to Research Program "Valere" supported by University of Campania "L.Vanvitelli".

Funding None.

\section{Compliance with ethical standards}

Conflicts of interest The authors declared that they have no conflict of interest.

Ethical standards This article does not contain any studies with human participants or animals performed by any of the authors.

\section{References}

1. Pan F, Ye T, Sun P, Gui S, Liang B, Li L, Zheng D, Wang J, Hesketh RL, Yang L, Zheng C (2020) Time course of lung changes on chest CT during recovery from 2019 novel coronavirus (COVID-19) pneumonia. Radiology. https://doi.org/10.1148/ radiol.2020200370

2. Cucinotta D, Vanelli M (2020) WHO declares COVID-19 a pandemic. Acta Biomed 91(1):157-160. https://doi.org/10.23750/ abm.v91i1.9397

3. Remuzzi A, Remuzzi G (2020) COVID-19 and Italy: what next? Lancet. https://doi.org/10.1016/S0140-6736(20)30627-9

4. Huang C, Wang Y, Li X, Ren L, Zhao J, Hu Y, Zhang L, Fan G, Xu J, Gu X, Cheng Z, Yu T, Xia J, Wei Y, Wu W, Xie X, Yin W, Li H, Liu M, Xiao Y, Gao H, Guo L, Xie J, Wang G, Jiang R, Gao Z, Jin Q, Wang J, Cao B (2020) Clinical features of patients infected with 2019 novel coronavirus in Wuhan, China. Lancet 395(10223):497-506. https://doi.org/10.1016/S0140 $-6736(20) 30183-5$

5. Song F, Shi N, Shan F, Zhang Z, Shen J, Lu H, Ling Y, Jiang Y, Shi Y (2020) Emerging 2019 novel coronavirus (2019-nCoV) pneumonia. Radiology 295(1):210-217. https://doi.org/10.1148/ radiol.2020200274

6. Bernheim A, Mei X, Huang M, Yang Y, Fayad ZA, Zhang N, Diao K, Lin B, Zhu X, Li K, Li S, Shan H, Jacobi A, Chung M (2020) Chest CT findings in coronavirus disease-19 (COVID19): relationship to duration of infection. Radiology. https://doi. org/10.1148/radiol.2020200463

7. Chung M, Bernheim A, Mei X, Zhang N, Huang M, Zeng X, Cui J, Xu W, Yang Y, Fayad ZA, Jacobi A, Li K, Li S, Shan H (2020) CT imaging features of 2019 novel coronavirus (2019-nCoV).
Radiology 295(1):202-207. https://doi.org/10.1148/radiol.20202 00230

8. Nardone V, Tini P, Pastina P, Botta C, Reginelli A, Carbone SF, Giannicola R, Calabrese G, Tebala C, Guida C, Giudice A, Barbieri V, Tassone P, Tagliaferri P, Cappabianca S, Capasso R, Luce A, Caraglia M, Mazzei MA, Pirtoli L, Correale P (2020) Radiomics predicts survival of patients with advanced non-small cell lung cancer undergoing PD-1 blockade using Nivolumab. Oncol Lett 19(2):1559-1566. https://doi.org/10.3892/ol.2019.11220

9. Li L, Qin L, Xu Z, Yin Y, Wang X, Kong B, Bai J, Lu Y, Fang Z, Song Q, Cao K, Liu D, Wang G, Xu Q, Fang X, Zhang S, Xia J, Xia J (2020) Artificial intelligence distinguishes COVID-19 from community acquired pneumonia on chest CT. Radiology. https:// doi.org/10.1148/radiol.2020200905

10. Rocha DM, Brasil LM, Lamas JM, Luz GVS, Bacelar SS (2020) Evidence of the benefits, advantages and potentialities of the structured radiological report: an integrative review. Artif Intell Med 102:101770. https://doi.org/10.1016/j.artmed.2019.101770

11. Agostini A, Floridi C, Borgheresi A, Badaloni M, Esposto Pirani P, Terilli F, Ottaviani L, Giovagnoni A (2020) Proposal of a lowdose, long-pitch, dual source chest CT protocol on third generation dual source CT using a thin filter for spectral shaping at 100 $\mathrm{kVp}$ for coronavirus disease 2019 (COVID-19) patients: a feasability study. Rad Med. https://doi.org/10.1007/s11547-020-01179 $-\mathrm{x}$

12. Brunese L, Mercaldo F, Reginelli A, Santone A (2020) Formal methods for prostate cancer Gleason score and treatment prediction using radiomic biomarkers. Magn Reson Imaging 66:165175. https://doi.org/10.1016/j.mri.2019.08.030

13. Bianconi F, Palumbo I, Fravolini ML, Chiari R, Minestrini M, Brunese L, Palumbo B (2019) Texture analysis on [(18)F]FDG PET/CT in non-small-cell lung cancer: correlations between PET features, CT features, and histological types. Mol Imaging Biol 21(6):1200-1209. https://doi.org/10.1007/s11307-019-01336-3

14. Neri E, Coppola F, Miele V, Bibbolino C, Grassi R (2020) Artificial intelligence: who is responsible for the diagnosis? Radiol Med. https://doi.org/10.1007/s11547-020-01135-9

15. Allam Z, Jones DS (2020) On the coronavirus (COVID-19) outbreak and the smart city network: universal data sharing standards coupled with artificial intelligence (AI) to benefit urban health monitoring and management. Healthcare (Basel). https://doi. org/10.3390/healthcare8010046

Publisher's Note Springer Nature remains neutral with regard to jurisdictional claims in published maps and institutional affiliations. 